\title{
Making Digital: Visual Approaches to the Digital Humanities
}

\author{
Gareth Beale \\ Archaeological Computing \\ Research Group \\ Archaeology, Building 65A, \\ University of Southampton, \\ Avenue Campus, \\ Southampton, SO17 1BF, \\ UK \\ gareth.beale@soton.ac.uk
}

\author{
Nicole Beale \\ Archaeological Computing \\ Research Group and Web \\ Science \\ Archaeology, Building 65A, \\ University of Southampton, \\ Avenue Campus, \\ Southampton, SO17 1BF, \\ UK \\ nicole.beale@soton.ac.uk
}

\author{
Ian Dawson \\ Winchester School of Art \\ Winchester School of Art \\ University of Southampton, \\ Park Avenue, Winchester, \\ SO23 8DL, UK \\ id2@soton.ac.uk
}

\author{
Louisa Minkin \\ Winchester School of Art
}

Winchester School of Art University of Southampton, Park Avenue, Winchester, SO23 8DL, UK

l.minkin@soton.ac.uk

\begin{abstract}
The Making History Project is an attempt by artists and archaeologists based within the University of Southampton to collaboratively develop innovative uses for 3D technologies. Techniques such as high resolution data capture and 3D printing represent a new era in digital imaging. As these technologies become increasingly affordable they are coming to play a more significant role in archaeological and artistic practice. Both art and archaeology are currently involved in attempting to realise the full implications and potential of these technologies. This paper describes a project undertaken by the Archaeological Computing Research Group and Winchester School of Art at the University of Southampton which seeks to address this moment of technological disruption in order to collaboratively develop creative and methodologically innovative approaches to the use of these technologies.
\end{abstract}

Archaeology. Art. 3D printing. 3D technologies. Collaboration. Interdisciplinary. Teaching. Learning.

\section{INTRODUCTION}

The introduction of $3 \mathrm{D}$ data capture technologies and $3 \mathrm{D}$ printing have begun to have an impact on practice in Art and in Archaeology. The increased availability of these techniques, as software usability improves and hardware costs lessen has been accompanied by a high level of interest from Art and Archaeology communities but also from the general public. This interest is without doubt justified. These technologies present the possibility of tactile engagement with data in a way that has never previously been possible. It is essential that engagement with this technology is critical, creative and grounded within good disciplinary practice, and that we avoid what Huggett (2004) termed the technological fetishism which often accompanies the introduction of technology to a discipline or area of study.

During this period of inflated expectations for 3D technologies, it is important that we identify tangible benefits resulting from the uptake of these technologies for both Art and Archaeology. This is in line with Gartner's technology adoption hype cycle (Fenn 2008). We must avoid a decrease in the use of potentially valuable tools as interest diminishes and enthusiasm wanes.
The Making History project is a collaboration between Winchester School of Art (WSA) and the Archaeological Computing Research Group (ACRG), both based at the University of Southampton, which seeks to drive the innovative and relevant use of these technologies. The project is formed of a number of event-based collaborations and sub-projects each of which give participants an opportunity to collaborate and to critically assess the potential use of technologies in their own and in each other's disciplines. The events are participatory and highly discursive allowing project members to think critically about the use of technology while sharing resources, expertise and disciplinary insights.

\subsection{Why Art and Archaeology?}

Archaeology and Art as disciplines have been intertwined for as long as both have existed together. At the most fundamental level, both have a shared focus on substance and materiality (Renfrew et al. 2004: 2). The value of the interplay between the two areas lies in the inherent reflexivity of the relationship. From the first works of antiquarian scholarship through to the present day, 
the influence of the Arts upon Archaeology has been profound (Renfrew 2003).

The way in which the past is represented and perceived has been characterised by a constant dialogue between Art and Archaeology and in many cases the active involvement of artists in the archaeological process (Smiles \& Moser 2005). The styles and conventions which characterise archaeological representation of all kinds (including illustration, printing, photography and computer graphics) were not developed in isolation but were honed and developed in response to, or alongside changing artistic practice and the changing aesthetic norms of society at large.

At the same time archaeology has also had a powerful influence upon art. Art objects might be considered historic documents in their own right; illuminating their context through the place, circumstance and conditions of production. Furthermore, the archaeological process itself is one of the key metaphors of modernity in art practice, encompassing measured relations to place and landscape as a cultural substrate. Use of the archaeological metaphor also has the capacity to invoke myths of origin, psychoanalytic excavations, and fragments of the Romantic.

Artists have long been fascinated by the processes of archaeologists and their antecedents. This association has been commonplace in twentieth century practice, from Picasso's use of 'primitive' ethnographic artefacts, to Hepworth, Moore and Nash's reflections on the ancient landmarks of the British landscape, and Deller's re-enactment of the Battle of Orgreave. Artists and archaeologists share a concern with making visible. The movement of images and gestures across cultures and historic eras demonstrates both an interest in the operations, ideology and figures of other times and spaces, and a sense of the importance of the historic transfer of process and technology and its operation in transforming practices and knowledge.

There can be little doubt then that the connections between archaeology and art are valuable in both a profound and highly practical sense. These connections have inspired thinkers and practitioners in both fields and have the capacity to continue to do so. The differing but closely related skillsets of artists and archaeologists can motivate creative approaches to practice on both sides. The potential which artists and archaeologists may identify in new technologies will almost certainly not be the same. It is highly likely that this difference of perspective will cause collaborators to review their assumptions and to think more creatively about the possibilities offered by these technologies. The main challenge of the Making History Project is to catalyse and to support multidisciplinary collaboration. In line with this, one of the goals of the project has been to develop the potential for collaborations of this type to occur within the university setting.

\subsection{Technologies and Academia: Adoption and Adaption}

Academic practice traditionally has been bound within disciplines, with each discipline preferring particular methodologies and methods for knowledge production and knowledge sharing. Multidisciplinary approaches have long been recognised as essential for solving research problems (Research Council UK 2012). At most universities this kind of working is encouraged and supported. But the institutional, cultural and funding settings must be developed to support rather than impede the type of relationships that will lead to such work being possible in order for multidisciplinary projects to develop collaboratively (Metcalf et al. 2006).

The Art and Archaeology relationship is an example of this working. Whether acknowledged or implicit, there has always been a link between these disciplines, and this link, and the potential for further explicit collaboration, is explored by the Making History Project.

Administratively, universities must be managed by research group, department or faculty, which often leads to barriers to working multidisciplinarily. The Making History Project aims to transverse these boundaries by providing opportunities for ideas and approaches to occur organically, and allowing for iterative development of project management. Within the Making History Project, two departments with different approaches to adopting technologies embarked on a journey to use an event-based relationship to enrich both departments' understanding of the possibilities of 3D technologies.

One key part of the project is to examine the use of 3D technologies within Art and Archaeology together. This investigation attempts to find a way to incorporate approaches from each department into each other's work. Whilst also collaboratively creating outputs together, with both students and staff. The intention is to find new ways to use 3D technologies that would not have otherwise been identified. 


\section{MULTIDISCIPLINARITY IN ACTION}

Traditionally multidisciplinary working involves project specific collaboration, closely tied to preagreed aims and objectives. Most projects are driven by one department, with other disciplines becoming involved as specialisms are required.

We did not want our collaboration to be based on merely explaining to each other how we work. It was essential that both disciplines have direct involvement in decision-making and in the identification of activities. In order for this to occur, we opted to organise a series of events at which archaeologists and artists could learn through participating in typical Art and Archaeology activities. The project began in April 2012 with meetings to discuss the potential for working together and arranging opportunities for staff and students to meet.

We began the project believing that Art and Archaeology have different, but overlapping goals. For Archaeology, a key goal was to develop new approaches to the creation and use of 3D data, and the use of $3 \mathrm{D}$ technologies, through collaboration and problem solving.

For Art, the goals could be described as being more vampiric than overlapping; participants from WSA sought to discover how archaeologists use new technologies for recording and exhibiting. It was hoped that the collaboration might provide new body of material for creative consumption, and that students and staff would discover new processes to adopt and adapt.

During initial planning meetings, the staff from WSA commented that artists thrive on dialogue, repurposing ideas and methodologies. The project embraced this as an essential part of the approach, encouraging students to fold these technologies into their vocabularies of making with confidence and agency and that this might happen best by sharing resources and expertise.

This is one of the first projects attempting to develop innovative approaches to cross-faculty collaborative research and education based around shared technology and expertise. The project has at its heart a focus on the development of better understanding of the opportunities and limitations that the 3D technologies being used offer for Art and Archaeology, both separately and together.

\section{3D TECHNOLOGY: DISRUPTION, INNOVATION AND PRACTICE}

$3 \mathrm{D}$ technologies have the capacity to revolutionise artistic and archaeological practice. The implications for each area differ greatly, but the opportunities for both areas can be more fully understood and more fully realised through coexploration. The following section will outline the opportunities which project participants perceive that 3D technologies will offer in their subject areas.

\subsection{Opportunities for Archaeological Practice}

3D data capture and 3D printing are relatively recent additions to the toolkit used by archaeologists. The potential of high resolution 3D data capture has been identified and exploited in a range of archaeological settings. Primarily the technique has been employed as a means of recording archaeological objects or environments. Despite the growth in the volume of $3 \mathrm{D}$ data being produced by archaeologists the range of techniques available which allow these data to be explored, interrogated or disseminated remains limited.

Traditional computer graphics techniques have been widely employed as a means of exploring and disseminating large 3D data sets. Dissemination has generally taken the form of animations or still rendered images which offer the viewer few options for engagement or interaction. 3D printing offers an alternative mechanism with which to explore and disseminate 3D data, however this technique has not yet been widely adopted.

3D printing offers the possibility of tactile, multisensory engagement with $3 D$ data. $3 D$ printed objects invite us to consider a range of factors relating to the feel, weight and materiality of the object in ways which have not previously been possible. In order to fully realise the potential of this technology and to fully appreciate its limitations it is important that archaeology confers with other disciplines, such as art, which have a similar focus on objects and their materiality.

\subsection{Opportunities for Art Practice}

The past decade has seen an exponential increase in $2 \mathrm{D}$ image transfer technology, from capture apparatus to compression codecs. New languages have opened up through the accessible transmission, manipulation and mediation of images, the boundaries of art practice have fallen. 
Technologies of reproduction produce societal change. They have affect. 3D technologies open up new ways again for us to think about fabrication, seriality, dissemination and multiples in art practice. There is an inherent shift from conventional structures of disciplinarity within an art school even in naming a ' $3 \mathrm{D}$ print'. The shift from discipline to digital infrastructure opens up the possibility of some inventive configurations, building unforeseen conjunctions and new spaces.

As artists it is novel to think that in observing, drawing or modelling we might be capturing, analysing and processing data. We are familiar with copies, traces, imprints, indexes. We know about practices of auto-composition that have a random or machinic element. Our work has been infected by the spaces of computer games. Military technologies have changed the configuration of spatial \& pictorial practices, re-imagining the thresholds of 'virtual' and 'real'. Complex, contradictory and fractured positions are generated, focussing viewer and author into the same space.

A 3D printer can realize impossible objects, those which cannot be cast otherwise; it can also make available replica objects to hold. Combined with traditional processes, it means that a fragile object can be 3D scanned, printed and then cast conventionally in the foundry to produce a material facsimile without damage or loss. It also allows objects produced by software to be transmitted and materialized.

For both artists and archaeologists alike, our image world is constructed by film industry CGI, advertising manipulations, social networking data bodies, spectacular projection mapping. We see an increasing use of consumer software to model spaces and objects, producing multiple camera positions, complex remixed spaces, armatures constructed as frameworks and skins. 3D scanning as a drawing tool allows us to insert complex representations into these geometric/ axonometric worlds, and vice versa. Understanding the technology that produces such strong and enchanted worlds, making it available, hackable, demystified seems vital currently.

\subsection{The Events}

The Making History Project is primarily eventbased. A series of major events have been carried out since April 2012, and are outlined below. With each event the collaboration develops further and additional ideas are explored and new pathway possibilities drafted.

\subsubsection{ACRG Lab Workshop: 3D Technologies for Artists}

A workshop organised by project members from the archaeological computing research group with attendees from WSA and the ACRG. The workshop was designed to encourage inter-disciplinary thinking on the potential uses of 3D technology for exhibition design for art and cultural heritage. Attendees formed groups and designed a hypothetical exhibition featuring 3D technologies such as 3D printing, projection mapping and computer graphics. The event drew upon the skills of attendees which included; exhibition design, sculpture, art history, printing, 3D graphic design, web design and theoretical approaches to Art and Archaeology.

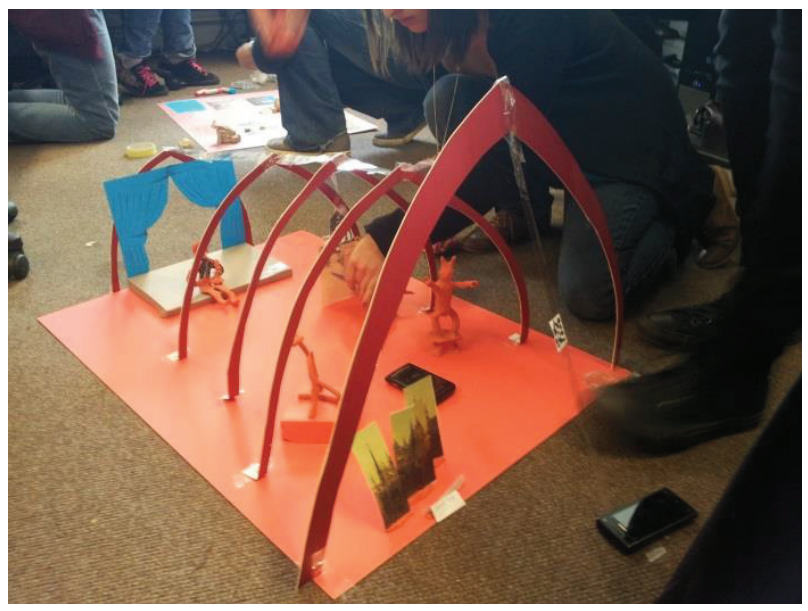

Figure 1: Students and staff from WSA worked in teams to produce maquettes for $3 D$ technologies use within cultural heritage themed exhibitions

\subsubsection{WSA Workshop: Printing for Archaeologists} Archaeology staff and PhD students spent a day in the Printmaking Workshop at WSA as part of our interdisciplinary exchange. The group brought images from their research including some from Basing House where our joint project will be conducted over the coming year. These images were layered up in screen-print to reinterpret the data files and offer new possibilities for composition and meaning. Copper plate etchings were made with the tools and objects that the archaeologists use in the field, leaving traces of trowels, measuring tools, underwater markers. The fingerprint and footprint appear regularly as traces in the sensitive surface of the soft ground, alongside contours from maps, details of diagrams and archaeological illustration.

As a counterpoint WSA staff and students made a study visit to the Victoria and Albert Museum in London. Students were asked to locate, observe and describe historic artefacts in the museum 
display cases. The same objects were then reinterpreted by another member of the group, producing different takes on the same material and making visible different aspects in which an object might be viewed.

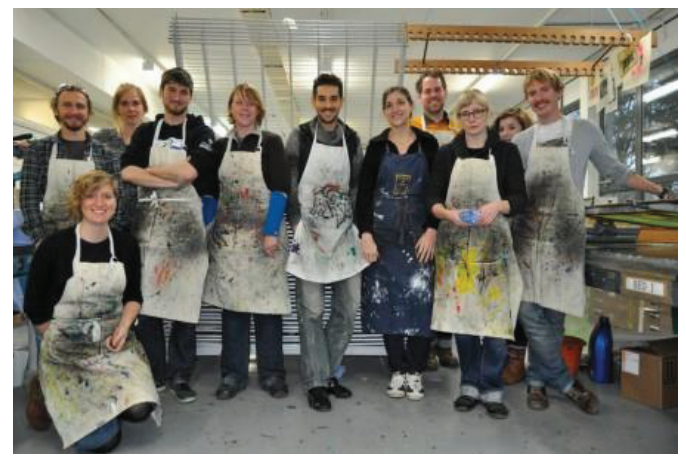

Figure 2: PhD Archaeology students with WSA staff

\subsubsection{Portus Head: Art and Archaeology}

The Portus head is a carved marble head, excavated by the University of Southampton Department of Archaeology team working at Portus, the ancient port of Rome. It is an iconic object, and has become the symbolic representation of the University's involvement in the project. Scanned and data captured by the ACRG and $3 D$ printed by WSA it is the first collaborative project between the two departments. Multiple copies were printed in various scales and were handled, discussed and disseminated throughout the university and externally. A print of the head was reformed as part of an artistic practice and a film of the 3D print process; the layering of the resin powder within the print bed and then the excavation of the 3D print became poetic counterpoints to the original excavation of the Portus head.
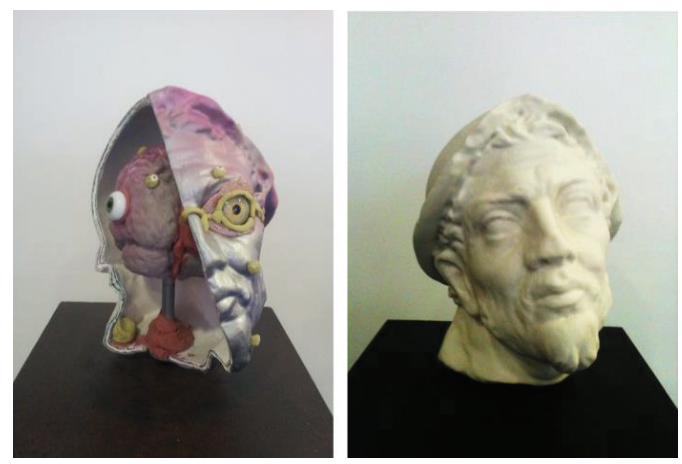

Figure 3: lan Dawson's work on display in the Humanities building at the University of Southampton

\subsubsection{Demo at WSA End of Year Show}

Our first semester this year was spent reconstructing a C19 3D prototyping apparatus.
Reconstruction is more familiar as a speculative practice in archaeology, but has proved a valuable pedagogical tool in art school. Students worked collaboratively to investigate and construct an ambitious, functioning apparatus, deducing its operation from photographs and period descriptions. In the process they learned construction techniques, documentation skills and research methodologies. Archaeology staff joined us for the final presentation with their RTI dome, a contemporary take on the same multi-viewpoint technology.

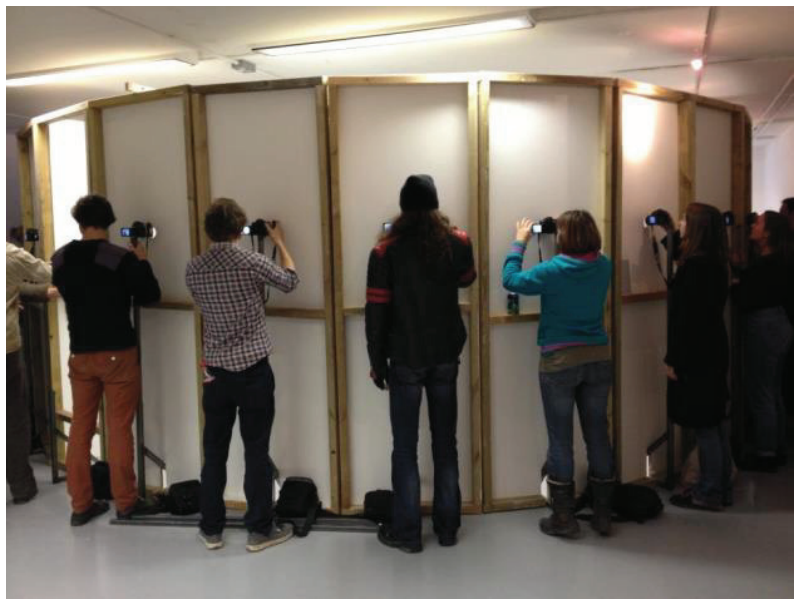

Figure 4: Art students simultaneously trigger camera, photographing a model seated inside the photosculpture apparatus. Photograph courtesy of Lesley Blakelock

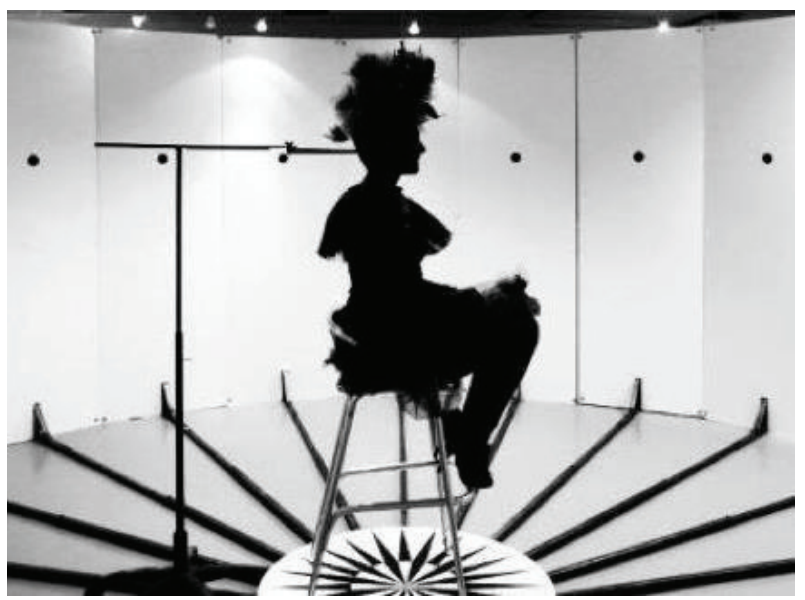

Figure 5: A model poses inside the photosculpture apparatus. Photograph courtesy of Matthew Goodsmith

As part of the demonstration organised at WSA, artworks created by art students were recorded by ACRG PhD students, using a form of computational photography, Reflectance Transformation Imaging $(\mathrm{RTI})$, as an experiment in the re-use of archaeological photographic recording techniques 
for the recording and sharing of three dimensional artworks.

\subsubsection{Stored Collections Visit}

WSA students and staff visited the stored collections of the Hampshire County Council Museums Service. Students were introduced to the stores, their taxonomy and structure as well as questions of collecting, archiving and accessioning artefacts. The day was framed around ways of looking at objects, collecting information, technical mediations. Groups rotated through RTI, 3D laser scanning and making drawings of objects from the Basing House site. Interestingly each process initiated different ways of handling the objects as well as documenting them, producing different forms of attention in the students. The artefacts themselves were very variable in their material qualities. The carved stone will inspire a new workshop at WSA.

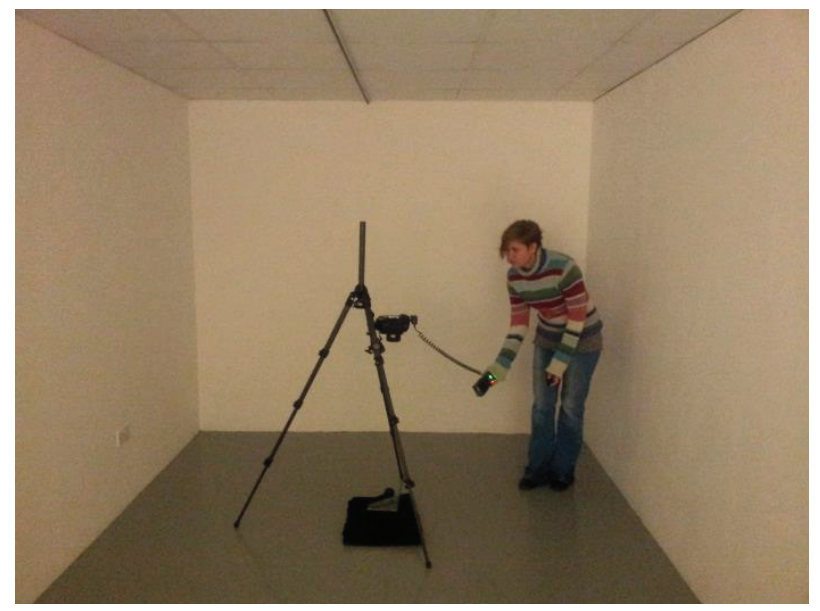

Figure 6: Recording art student artworks at WSA

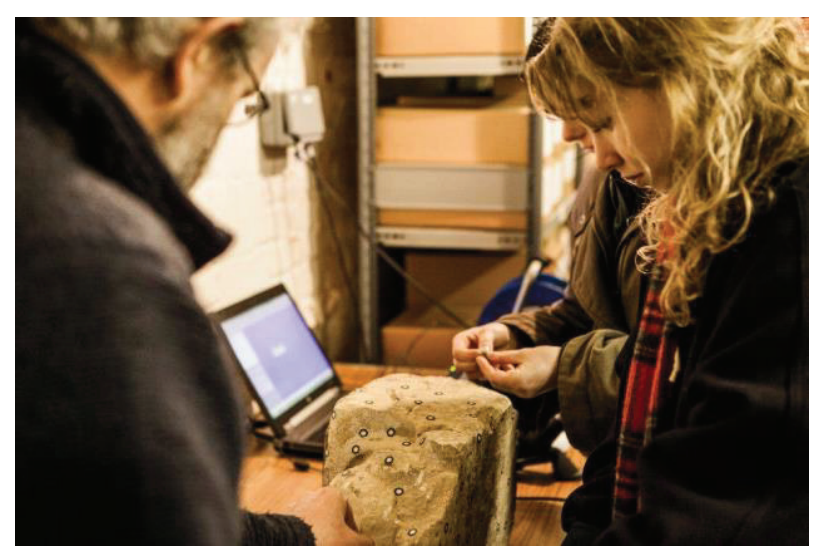

Figure 7: WSA students laser scan an artefact at the collections stores in Winchester. Photograph courtesy of Alick Cotterill

\subsection{6. 'How to' Advice for Art/Archaeology Transition Students}

An unanticipated outcome of the Making History Project has been the increase in requests from students for career or study advice relating to subjects outside of their originating discipline. Undergraduate art students have asked for advice on taking up postgraduate studies within archaeology, and postgraduate archaeology students have requested training in art techniques to complement their research.

\subsubsection{Basing House Excavation}

One major event planned as part of the Making History Project is a collaboration between Art and Archaeology students scheduled to take place in July to August 2013. During an undergraduate Archaeology student training excavation at Basing House in Hampshire, art students and staff will work with archaeology students and staff to produce creative interpretations of many of the artefacts and features at the site, including decorative stonework, corbels, standing building remains, earthworks, and the excavations themselves.

The outputs will involve the use of technologies such as computational photography (including photogrammetry and RTI) along with on-site workshops introducing 3D technologies software (such as 123DCatch and Google SketchUp). Subprojects include the development of models for printing and $3 \mathrm{D}$ projection that are based on laser scans of a large LEGO model of a reconstruction of the site from the sixteenth century and recording corbels using photogrammetry for the reworking of meshes using 123DSculpt.

There will also be an Artist in Residence scheme over the duration of the excavation, giving art students an opportunity to work closely with archaeologists to make alternative recordings of the excavations.

\subsubsection{Exhibition at Winchester Discovery Centre, Milestones Museum and Willis Museum}

Outreach and education events for the public will be organised by archaeology and art students regularly throughout the season, with an emphasis on working together to produce reusable outreach activities for Hampshire County Council Museums Service. Students will work with the county Conservator and Keeper of Archaeology, as well as specialists from the curation and exhibition team at Hampshire County Council. One major outreach event is a planned exhibition of the outputs from the students' time at Basing House, scheduled to be staged late summer at various cultural heritage exhibition spaces. The exhibition will have 
components that will be on display at both WSA and the ACRG computer laboratory.

\subsubsection{INTECH Science Centre After Dark}

Public Outreach events are planned throughout the excavation at Basing House for archaeology and art students to experiment with producing models and images using 3D technologies for Art and Archaeology subjects. In addition to this a one-off experience is scheduled for June 2013 at INTECH Science Centre's After Dark event, targeted at adults wishing to learn more about science in creative ways. Working together, archaeology and art students will develop activities to introduce 3D technologies to visitors to the event.

\subsubsection{Development of Art/Archaeology Course}

Collaborations have led to a planned course to be jointly taught by WSA and Archaeology staff, exploring the relationship between Art and Archaeology.

\section{REFLECTING ON COLLABORATION}

\subsection{In Each Other's Shoes}

One of the most effective dimensions of the collaboration has been the opportunity to engage in the working practice of a separate discipline. Activities such as the workshops held at WSA and Archaeology have given researchers the chance to work with techniques and concepts with which they are not necessarily familiar and to reflect upon their own disciplinary practice from the outside. The value of these activities to participants is demonstrated in the rage of collaborations which have emerged from initial workshops and activities. These have led to several instances in which researchers and students have modified or adapted their working practice in line with new insights. Many of these activities are outlined above, including the creation of collaborative exhibitions such as the Portus Head installation and the print exhibition at the Vice Chancellor's residence these activities will culminate in the first University of Southampton joint Archaeology and Art summer fieldwork project at Basing House.

\subsection{Outputs and Communication}

Communication sits at the heart of both art and archaeology. Communicating using 3D technologies (or communicating the ways in which we use them) must now be at the heart of both disciplines.

Established archaeological modes of representation have been called into question through collaboration with WSA. Artists might be equally interested in the failures of communication, glitches, noise, overloads, and the impulsive. While archaeology tends to focus upon the use of established modes of representation in order to convey information. Considering archaeological processes from the perspective of the arts has had a significant impact upon archaeological practice and has led to development of a more critical approach towards the capture, processing and dissemination of data. An example of this has been the processing of 3D data. A 3D scan or printed model has to be cleaned up in the same way that a bronze cast must be worked on after initial casting. The Portus head installation provided a vehicle through which to explore this observation and to convey these ideas to the public. The exhibition was based upon the notion that irritation can be as useful as rapport. In providing a visual counterpoint between conventional archaeological representation and a highly modified, personalised version of the same object the exhibition invited the public to consider the nature of mechanical reproduction using $3 \mathrm{D}$ printing while also calling into question normative modes of archaeological representation.

This is just one example of the disruptive influence which collaboration can have upon working practice. Collaboration has offered participants the chance to question the technical inscription of cultural objects as models, projections and simulations and to explore these ideas in a public forum communicating with a wider audience than would ordinarily be the case. The collaborative development of outputs which are designed to engage audiences outside of Art and Archaeology will remain at the heart of the Making History project and will expand as the Basing House fieldwork project begins this summer.

\subsection{New Methodologies}

Archaeology and art both have established and conventionalised methodological approaches. One of the dangers implicit in the adoption of new technology is that established methodological approaches are uncritically applied in scenarios where they are inappropriate or do not adequately confront the demands or exploit the possibilities of new technology. A central challenge of technological innovation in Art and in Archaeology is to ensure that methodological approaches are appropriately modified while also avoiding uncritical acceptance of the methodological, cultural and conceptual baggage which often accompany technological change.

Sterne (2003) argues that the best way in which to avoid succumbing to the accepted wisdom and 
hype which surrounds new technology is to adopt a reflexive approach to methodological development; much like the reflexive sociology championed by Bourdieu. The Making Histories project should be seen as an attempt to enhance the capacity of Art and Archaeology to be receptive to the benefits of 3D technologies while remaining critically aware and so (we hope) remaining partially immune to the blind methodological alleys which technological novelty and/or methodological dogma can lead.

There is great creative potential in the development of hybrid methodological approaches through critical interdisciplinary discourse. Each of the events and sub projects which constitute the Making History Project has led to the development of innovative and self-aware methodological approaches. The scale, scope and lifespan of these methodologies is highly variable and often highly unpredictable. It will perhaps be possible to judge the degree to which these approaches are successful in retrospect but for now the goal of this project should be to continue to provide a space within which these interactions can continue to take place and within which ideas can be developed, expanded and adapted.

\section{REFERENCES}

Fenn, J. (2008) Understanding Gartner's Hype Cycles, Gartner Inc.

http://www.gartner.com/DisplayDocument?doc cd= 158921\&ref=g noreg (retrieved 1 April 2013)

Huggett, J. (2004) Archaeology and the new technological fetishism. Archeologia e Calcolatori, 15, 81-92.
Metcalfe, J., Riedlinger, M., Pisarski, A., Gardner, J. (2006) Collaborating across the sectors. The relationships between the humanities, arts and social sciences (HASS) and science, technology, engineering and medicine (STEM) sectors. Council for the Humanities, Arts and Social Sciences, CHASS Occasional Paper \#3.

http://www.chass.org.au/papers/PAP20061101EA. php (retrieved 1 April 2013)

Renfrew, C. (2003) Figuring It Out: What Are We? Where Do We Come From? The Parallel Vision of Artists and Archaeologists, Thames \& Hudson, London.

Renfrew, C., Gosden, C. and DeMarrais, E. (2004) Substance, Memory, Display: Archaeology and Art. McDonald Institute for Archaeological Research, University of Cambridge, Cambridge.

Research Council UK (2012) Impact Report 2012. Research Council UK.

http://www.rcuk.ac.uk/Documents/publications/Imp actreport2012.pdf (retrieved 1 April 2013)

Smiles, S., Moser, S. (eds.) (2005) Envisioning the past: archaeology and the image, Blackwell, Oxford.

Sterne, J. (2003) Bourdieu, technique and technology, Cultural Studies, 17, 3/4, 367-389. 